\title{
Some Prerequisites to Cooperative Cataloging
}

BY RITVARS BREGZIS

A COOPERATIVE cataloging center that would be equipped to process efficiently and quickly current non-American materials acquired by our research libraries would be of immeasurable help. The plans for such a center suggested by Ralph E. Ellsworth ${ }^{1}$ and the Library of Congress $^{2}$ merit attention and detailed study. If such a center can be established, either as part of the Library of Congress or outside of it, library administrators should act promptly and decisively. The high cost of original cataloging of identical materials in many libraries and the mounting of backlogs in most catalog departments are compelling reasons for urgent action.

The proposed plans suggest two basic alternatives: centralized cataloging, or dispersed and coordinated cataloging. The former alternative assumes that the library first acquiring a given item forwards it to the proposed center for cataloging; the latter alternative prefers that the proposed center function as a clearinghouse receiving and distributing requests for cataloging to be performed by the library first acquiring the given item.

Both of these alternatives have their advantages and their disadvantages. The coordinated cataloging plan which is an expanded National Union Catalog technique would require a relatively smaller capital investment since most of the cataloging would be done by the larger re-

\footnotetext{
${ }^{1}$ Ralph E. Ellsworth, "Another Chance for Centralized Cataloging," The Colorado Academic Library, I (Fall 1963), 1-4.

2 United States Library of Congress, Items suggested for Agenda of ARL, Midwinter Meeting, 1963-1964 (Draft), 1964.
}

Mr. Bregzis is Head of the Catalog Department in the University of Toronto library.

search libraries. Its principal disadvantages seem to be the burden on the larger research libraries and above all the resulting nonstandard entries which in practice, although helpful, have proved to require considerable additional cataloging effort on the part of the recipient library. The larger library in particular feels this nonstandard entry to be short of the expected and required form. Moreover, whether this complex scheme can be made to work with sufficient speed is doubtful as the success of the scheme would depend on work in many individual catalog departments laboring under a variety of different handicaps and pressures.

The centralized cataloging concept seems to be more promising, as there would be only one system with its complexities to contend with. However, even in this concept the principal factor, at least for the larger library, seems to be the expeditious lending of the copy for cataloging with its attendant problems, rather than the cost of this service. A $\$ 20,000$ per annum service charge would be amply justified if in return the library could receive proof slips for some 40 per cent of new titles acquired.

As the plan suggested by the Library of Congress has indicated, there would be a great number of technicalities to be agreed upon by the participating libraries and many details to be worked out. The scope of the proposed plan would have 
to be defined, as it may not be feasible to include materials that are not likely to be acquired by at least several libraries. More important still is the system of records that would have to be designed to control the lending of the items to the center for cataloging. Many research libraries will have automated acquisitions control in operation within the next few years. Provision for compatibility of mechanized records is an important factor to consider. Similarly, very important and not easily resolved is the problem of insuring uniformity of the interpretation and application of the rules governing entry, classification, and subject analysis between the participating libraries and the center.

It will be a difficult task for the center to design the entry, classification, and subject headings acceptable in the catalogs of any one and all of the participating libraries. A great deal more standardization of rules in these three key areas and a standardized code of interpretation of these rules would have to precede any cooperative effort if the participating libraries are to expect the cataloging done by the center to be reasonably acceptable and therefore economical. In libraries that presently "follow LC" in entry, classification, and subject heading there is ample evidence that the merging of LC authority with the local authority for entry, interpretation of classification, and application of subject headings produces considerably less than duplication of the LC system, although the aim and rule is to follow LC. The reasons for this growing incongruence are well known. The entry that LC establishes today in a certain form may already exist in a slightly variant form in the catalog of the participating library, which had to establish it in the absence of any record of this entry in the LC catalogs. The new LC proof slip or card now presents a conflict of entry, and the library is faced with two choices: either to modify its existing records under this entry to correspond with the LC form, or to adhere to its own form and decide to modify all future LC cards under this entry. Both are costly and uneconomical alternatives. The same problem exists in the area of classification, and to a lesser extent in that of subject heading use.

The cooperative system would have to find a solution to this problem of identical interpretation of cataloging rules; without it much of the benefit of cooperation would be lost. It should also be mentioned that the rules of entry, classification, and subject analysis presently in force vary from library to library, and the integration of bibliographical data emanating from the center into the large existing files of the participating libraries may be a task for which the librarian's art is hardly prepared with the present tools of bibliographical control.

This brings the proposed scheme of cataloging cooperation and centralized cataloging face-to-face with the conventional systems of bibliographic control and the form of catalog record which the participating libraries do and will wish to receive.

The impact of electronic data processing on library techniques has just begun to be felt in its relatively milder forms: circulation control, indexing, simple information retrieval, and lately attempts to automate the compilation of catalogs. The initial success in these areas seems to indicate that within the next few years there will be a pronounced turn toward the automated catalog. The number of libraries that today would like to receive the catalog record in machine useable form in preference to proof slips or printed cards is still small. But there seems to be little doubt that this number will increase rapidly. Therefore the catalog record produced by the cooperative center would have to be available both in printed card and in machine useable form.

It is this need for a machineable bibli- 
ographic record that amplifies the problems which librarians have attempted for half a century to resolve by codifying and systematizing their methods of bibliographical control. Considerations of bibliographic service and economy require a machineable record that is based on a logical and uniform system of entry, systematization of subject matter, and systematic terminology control (subject headings). Present experience with automated catalog design indicates, however, that the existing rules of entry, most classification systems, and subject heading systems incorporate logical and structural deficiencies that prohibit the automation of bibliographical control to work with effectiveness comparable to that of the available electronic data processing equipment. Automation applied to the existing systems of entry, classification, and terminological analysis may be likened to the installation of a jet engine in an ox cart set on a superhighway.

The present systems of bibliographic control-i.e., entry, classification, subjects-do not incorporate a structural design that would allow a logical summation, specification, and association of concept within the whole spectrum of the system. Thus the structure of all conventional title entries or all corporate entries of one kind is not identical. There are many rules that determine the choice and form of entry for an institution, and too much is left to the discretion of the cataloger. Thus entries for all conferences in a given field cannot be mechanically summarized without involving human effort. The result is the individual coloration of bibliographic control in each library to a degree that hinders cooperation through automated bibliographic record exchange.

Similarly, all library classification schemes, with the possible partial exception of the colon classification, are built predominantly on arbitrary and superficial arrangement of subject matter, and they do not permit systematic representation of the subject matter in its correct structure and context.

Thus the structure that underlies the classification of the history of fifteenthcentury England has little in common with that of nineteenth-century England, or with fifteenth-century Germany, or with nineteenth-century Russia. The lack of common structure to the scheme for fields prevents any automated approach to the information which has been classified purportedly with the aim of systematization. A classification system that aspires to be an effective counterpart of the electronic machine should incorporate logic that permits effective search by a single country, selected countries, or all countries; or search by period of any degree of generalization or specification; or search by any other desired qualification.

A classification structure that has been designed to reflect the prevailing philosophy of organization of subject fields obviously cannot fulfill such a function. Required is a system of a more basic structure, a system that ceases to be lineally heirarchical and can function as a heterogeneous logical complex of various aspects. Recent research in classification theory seems to indicate that this structure of concepts can be substituted for conventional structurization of subject fields. In our example-history, England, Germany, Russia, fifteenth-century and nineteenth-century are concepts each of which can be considered individually as elements of a classification system. Any combination of these concepts with the aid of any one of a limited number of forms of relationships between concepts should be designed to result in a heterogeneous system which would respond to systematic, multiple, specific, or generalized search that could be conducted for any concept, or group of concepts, or any concept in specified relationship with any other concept. 
Such a classification structure would not only be ideal for the automated handling of bibliographical information; it would in addition convert the conventional system of subject headings, or its improved version of descriptors, into a conceptual system of terminology. Such a terminology system could be used in conjunction with the concept classification system and serve as a terminological index to that system. This would permit direct conversion from terminology to classification, or from classification to terminology. It is interesting to note that some of our subject heading lists have attempted to do this by indicating the corresponding classification numbers where the logic of the subject heading and the logic of the class correspond. It is suggested that such correspondence within the entire system is essential.

It is in these three key areas, then, that automation is revealing the fundamental importance of the dormant problems of bibliographical control. If, along with cooperative recording of bibliographic information in the conventional form, automation is considered as an inescapable development, one cannot avoid seeing the depth of the problem which may not require altogether different parameters of bibliographical control but does require a basis that equals the automated methods in power of logic.

Apart from these problems of bibliographic representation any serious effort to establish cooperative processing or bibliographic information transmission on an automated basis will require a standard bibliographic data format that lends itself to direct recording and reading by data processing equipment. Such a standard data format would permit a mechanized exchange of cataloging data, it would assure a certain minimum of completeness of bibliographic data, it would permit programed editing in order to produce the bibliographic forms required by the individual library, and it would provide compatibility that would permit each library to choose its own definitions of bibliographic completeness and specificity for its own material, but it would also facilitate mechanical exchange of bibliographic information between libraries.

In conclusion, there appear to be two levels of problems that would have to be resolved before cooperative cataloging could become the efficient, quick, and lasting benefit it is expected to be. The first of them concerns technicalities of various kinds that are related to and implied in the conventional system and form of cataloging. These problems should not be impossible to solve given a genuine will for cooperation and ingenuity for simplicity and economical feasibility.

The second level of problems concerns cooperation viewed in broader perspective. It recognizes the fact that conventional methods of cataloging which already are overtaxing the capacity of most catalog departments, buried under mountains of books and avalanches of catalog cards, will not be much longer capable of solution by further increasing library staffs and the complexity of their work. It appears reasonable to assume that different approaches will have to be taken and that some of the very basic systems of bibliographical control will have to be re-examined. It is suggested that these basic systems could benefit from the logic and consistency that is implied in and suggested by modern data processing.

In view of these comments it may be suggested that, before our libraries begin hammering out the technical details of cooperative cataloging, librarians-and library administrators in particularshould concern themselves with a basic re-evaluation of the conventional philosophy of bibliographic organization. The cooperative cataloging that we plan to establish should serve the needs of tomorrow as well as those of the present day. 